\title{
Socioeconomic Disparity and Depression Among Internal Migrant Workers In Myanmar
}

\author{
Yi MS ${ }^{a}$, Wongsa $L^{b}$, Kittipong $S^{c}$ \\ aUniversity of Public Health, Yangon, Myanmar \\ ${ }^{\mathrm{b}}$ Faculty of Public Health, Khon Kaen University, Thailand \\ 'Thakhantho District Public Health Office, Kalasin Province, Thailand
}

\section{ABSTRACT}

Background: Over the past few decades, Myanmar has faced mass internal migration to seek job opportunities and pursue a better life. Migration gives rise to unambiguous stress and depression. This study aimed to assess the magnitude of depression and to identify the association between socioeconomic disparity and depression among migrant workers in Myanmar. Methods and Materials: Cross-sectional study was done among 1,201 migrants in Yangon Region. To assess the socioeconomic status, mental health status, accessibility of health care service and Quality of Life by developing self-administered questionnaire. The Generalized Linear Mixed Model was applied to determine the association between socioeconomic disparity and depression after adjusting for other covariates. Result: Their average age was $31.44 \pm 10.31$ years. Gender distribution was not much different. About one third of respondents were factory workers and had low level of education. The magnitude of depression was $38.22 \%(95 \% \mathrm{Cl}=35.50-41.00)$. Regarding the socioeconomic disparity, adequacy of income $(\mathrm{AOR}=1.79,95 \% \mathrm{Cl}: 1.35-2.37, \mathrm{p}$ value $<0.001)$ and floor surface area of the houses $(A O R=1.21,95 \% \mathrm{Cl}: 1.00-1.47, \mathrm{p}$ value $<0.001)$ were strongly associated with depression. Moreover, other factors that were associated with depression were stress, quality of life and burden of medical service cost. Conclusion: Two-fifth of internal migrant workers suffered depression. The findings highlighted to develop intervention aimed to improve mental health status among migrants. In order to achieve the sustainable development goals, it is important to make investment on mental health of the migrant workers.

KEYWORDS: stress, depression, socioeconomic disparity, migrant workers

\section{INTRODUCTION}

Rural to urban migration has contributed to the explosive growth of cities all over the world. With rising globalization and urbanization, there is an increasing need to realize mental health with several aspects of migrant health. ${ }^{1}$ Migrants are principally vulnerable to health problems. ${ }^{2}$

Since 2015, mental health and well-being promotion, prevention and treatment of substance abuse were included as health priorities in Sustainable Development Agenda and in goal 3 of the 17 SDGs focuses specifically on ensuring healthy lives and promoting well-being for all. The effect of

Corresponding author:

Dr. Yi Myint Swe

No. 43, Themainbayan Road,

Tarmwe Township, 11211 Yangon, Myanmar.

Tel No: +9595053113

Email: yimyintswe73@gmail.com human migration on mental health is multifaceted and has multicultural differences. ${ }^{3}$ Kirmayer et al identified several migration-related factors that could influence mental health. ${ }^{4}$ Among mental health problems, depression is most common at the workplace, then chronic disability and leading to huge economic burden globally. ${ }^{5}$ But if no action was taken to tackle the issue of depression, it can greatly worsen their quality of life. ${ }^{6}$

Currently, only limited data are available on the magnitude of depression and its associated factors among internal migrant workers in Myanmar. Internal migrant workers were chosen as a priority group because they were living under highly stressful situations and needed to be addressed, especially in internal migrant population which was $25 \%$ of internal migrant people migrate to Yangon. Hence, this study aimed to explore the magnitude and associated factors of depression among internal 
migrant workers in Myanmar. The findings of the study will contribute to formulate specific measures to reduce depression among migrant workers even though they are vulnerable population.

\section{METHODS}

This cross-sectional study was conducted in 2018 at North and East Districts among four districts namely East, West, North and South of Yangon Region.

\section{Study participants}

The inclusion criteria were migrant workers with the aged between 18 to 59 years living in Yangon Region, Myanmar, could verbally communicate with the researchers and agree to participate in this study. The exclusion criteria were migrant workers who didn't give the informed consent, seasonal workers and those with severe impairment and/or having mental illness.

For identifying the associations between numerous independent variables and a dichotomous outcome of depression, multiple logistic regression was used to estimate the sample size. The estimated sample size was 600 . In order to control the over-fitting, we used $\rho, 0.5$ and variance inflation factor (VIF) $2.00 .^{7}$ Thus, the total participant was 1201. A multistage random sampling method was used.

Firstly, Yangon was purposively selected because 25 $\%$ of internal migrant people migrate to Yangon. Then two other districts were randomly selected namely, East and North districts. After that two townships (sub-districts) from each district were randomly selected namely Hlaingtharyar and Shwepyithar from North District and Dagon East and Dagon Seikkan from East District. Therefore four townships (sub-districts) were included in the study. Finally, two communities were randomly selected from each township. Then participants were selected proportionate to the size of the study population. All participants were interviewed by trained interviewers.

\section{Research tools}

A structured questionnaire was developed from reviewing literature as the research tool. The content of questionnaire was validated by 3 experts and then it was revised. For The questionnaire was tested for using Conbach alpha among 30 participants in Thaketa township. Its Conbach alpha coefficient was 0.7 . The questionnaire consisted of five parts: (1) socioeconomic (2) health behavior (3) mental health (4) accessibility to health services; and (5) quality of life.

\section{Assessment of Depression}

Burmese version of the Centre for Epidemiological Studies Depression Scale (CES-D): which is a 20 -item self-report questionnaire to assess depressive symptoms using a four-point rating scale. Total score can vary between 0 and 60 . A cut point of 16 or greater $(=16)$ is defined as depression in Myanmar migrant population. In the bivariable and multivariable analysis, we dichotomized the presence or absence of depression.

\section{Assessment of Stress}

PSS (Perceived Stress Score) was used to assess the Perceived stress which contains 10 questions, each answer being scored from 0 to 4 . It is not a diagnostic instrument, but intended to make comparisons of subjects' perceived stress related to current objective events. The higher the degree and longer the duration of self-perceived stress, indicated by a higher score. The scores are categorized into three groups: low stress $(0-13)$, moderate stress (14-26), high perceived stress (2740).

\section{Assessment of quality of life}

QOL was assessed by using (WHOQOL- BREF) of WHO Myanmar short version. ${ }^{8}$ It consists of 26 items within the 4 domains containing physical, psychological, social relationships and environment domains. The scores are categorized into 3 groups: good level (96130 scores), moderate level (61-95 scores) and poor level (26-60 scores).

\section{Socio-economic status (SES) and Health service accessibility factors}

Socio-economic status composed of age, gender, marital status, educational attainment, occupation, house ownership, relationship with family members, floor surface area, monthly income, monthly expenditure, adequacy of income, time to reach the health service center, burden of transportation cost 
and medical service costs, support for transportation cost and medical service costs were treated as covariates in the analysis.

To minimize information bias, structured questionnaire interviewed by well-trained and standardized interviewers.

\section{DATA ANALYSIS}

Data were analyzed by STATA $®$ (ver. 13; College Station, TX, USA: Stata Corp). The categorical data were presented as frequency and percentage whereas the continuous data were described their magnitude as mean, standard deviation, median, and range. The Generalized Linear Mix Model was operated to model the random effects and correlations inside clusters. In GLMM modeling, the residential area (community) of the participant was set as the random effect. Bivariable analysis was utilized to express the association of each independent variable with depression. The factors with $p<0.25$ in the bivariable analysis were proceed to the multivariate analysis.

The results of final model were presented the magnitude of association of independent variables and depression as adjusted odds ratio (adjusted OR) and $95 \% \mathrm{Cl}$.

\section{ETHICS STATEMENT}

The proposal and tool of this research got approval from the University of Public Health, Yangon, Myanmar (ITERB-2018/Research/17) and Khon Kaen University Ethics Committee in Human Research (the approval number, HE 612079). A coding scheme was used in data collection and every documents relating to the participants were destroyed after completion of research. Written consent was obtained from all participants prior to participation.

\section{RESULTS}

The mean age with standard deviation of migrant workers in this study was $31.44 \pm 10.31$ years and gender distribution was not too much different but more than half of respondents were married. Nearly three fifth of participants were primary and secondary school education level. One third of respondents were factory workers. Only $11.24 \%$ owned their houses. Nearly $35 \%$ of the migrants lived in a house with floor area of less than $30 \mathrm{~m}^{2}$. Among the migrants, nearly $90 \%$ were related and breathed in a house.

In this study, $71.28 \%$ of migrants responded that their monthly total family income ranged between USD 130 - USD 230 with median monthly family's income of USD 200. Nearly half of the respondents said that they had no financial problem but can't save money.

Only $14 \%$ of migrants drank alcohol but most were within moderate stressful conditions, moderate level of quality of life and no burden of medical services costs.

Table 1: Number and percentage of depression among migrants in the Yangon Region of Myanmar $(n=1,201$

\begin{tabular}{llll}
\hline Depression & Number & Percent & $95 \% \mathrm{Cl}$ \\
\hline No (CESD <16) & 742 & 61.78 & $58.99-64.49$ \\
$\begin{array}{l}\text { Yes }(C E S D \geq 16) \\
\begin{array}{l}\text { Mean } \pm \text { standard } \\
\text { deviation }\end{array}\end{array}$ & 459 & 38.22 & $35.50-41.00$ \\
$\begin{array}{l}\text { Median (Min : } \\
\text { Max) }\end{array}$ & $13.30 \pm 8.8$ & \\
\hline
\end{tabular}

Seeing the depression status mostly had no depression $61.76 \%$ and the rest $38.24 \%$ were highly depressive conditions.

After doing the bivariate analysis that floor surface area of their houses, monthly family income and adequacy of income were strongly associated with depression. Also, gender, education, house ownership, relationship of family members, stress, time to reach the health service center, burden of transportation cost and medical service costs were also associated with depression.

Multivariable analysis for associated factors of depression, GLMM was performed to control the clustering effect of the sampling method in selecting the participants. The associations between multiple independent variables and depression was determine by using multivariate analysis to control the effect of covariates. 
Table 2: Crude odds ratio obtained from performing bivariate analysis of each factor and Depression $(n=1,201)$

\begin{tabular}{|c|c|c|c|c|c|}
\hline Characteristics & Number & $\begin{array}{c}\% \text { of } \\
\text { Depression }\end{array}$ & OR & $95 \% \mathrm{Cl}$ & $P$ value \\
\hline 1.Age (yr) & & & & & 0.92 \\
\hline$\leq 35$ & 808 & 61.66 & 1 & & \\
\hline 2. Gender & 393 & 61.98 & 1.01 & $0.79-1.31$ & 0.043 \\
\hline Male & 547 & 35.63 & 1 & & \\
\hline Female & 654 & 41.32 & 1.27 & $1.01-1.60$ & \\
\hline 3. Marital Status & & & & & 0.157 \\
\hline Married & 685 & 36.50 & 1 & & \\
\hline $\begin{array}{l}\text { Unmarried(Single Separate/ } \\
\text { Divorced) }\end{array}$ & 516 & 40.50 & 1.18 & $0.94-1.50$ & \\
\hline 4. Education & & & & & $<0.001$ \\
\hline Low & 415 & 34.05 & 1 & & \\
\hline High & 786 & 41.48 & 1.50 & $1.17-1.93$ & \\
\hline 5. Occupation & & & & & 0.064 \\
\hline Regular income job & 606 & 35.64 & 1 & & \\
\hline Irregular income job & 595 & 40.84 & 1.25 & $0.99-1.53$ & \\
\hline 6. House ownership & & & & & 0.001 \\
\hline $\begin{array}{l}\text { Rent from others/Live in infor- } \\
\text { mal setters and relatives' houses }\end{array}$ & 1066 & 36.59 & 1 & & \\
\hline House owner & 135 & 51.11 & 1.81 & $1.26-2.60$ & \\
\hline 7. Floor area of the house $\left(\mathrm{m}^{2}\right)$ & & & & & $<0.001$ \\
\hline$>100$ & 392 & 28.32 & 1 & & \\
\hline$\leq 100$ & 809 & 43.02 & 1.91 & $1.47-2.48$ & \\
\hline 8. Related & & & & & 0.04 \\
\hline No & 138 & 30.43 & 1 & & \\
\hline Yes & 1063 & 39.23 & 1.47 & $1.01-2.16$ & \\
\hline $\begin{array}{l}\text { 9. Family monthly income } \\
\text { (MMKs) }\end{array}$ & & & & & 0.19 \\
\hline High income >350000 (>USD 230) & 345 & 35.36 & 1 & & \\
\hline Low income $\leq 350000(\leq$ USD 230$)$ & 856 & 39.37 & 1.18 & $0.92-1.54$ & \\
\hline $\begin{array}{l}\text { 10. Family monthly expenditure } \\
\text { (MMKs) }\end{array}$ & & & & & 0.137 \\
\hline Low <200000 (<USD 130) & 381 & 35.17 & 1 & & \\
\hline High $\geq 200000(\geq$ USD 130) & 820 & 39.63 & 1.21 & 0.94-1.59 & \\
\hline 11. Adequacy of income & & & & & 0.047 \\
\hline Enough with or without saving & 1040 & 37.12 & 1 & & \\
\hline Not Enough with or without debt & 161 & 45.34 & 1.4 & $1.01-1.96$ & \\
\hline 12. Alcohol Drinking & & & & & 0.19 \\
\hline No & 1,035 & 37.49 & 1 & & \\
\hline Yes & 166 & 42.77 & 1.25 & $0.89-1.74$ & \\
\hline 13. Stress & & & & & $<0.001$ \\
\hline Low stress & 125 & 20.80 & 1 & & \\
\hline High stress/ moderate & 1,076 & 40.24 & 2.56 & $1.63-4.02$ & \\
\hline 14. QOL & & & & & $<0.001$ \\
\hline High & 322 & 24.22 & 1 & & \\
\hline Low/ mode & 879 & 43.34 & 2.39 & $1.79-3.19$ & \\
\hline $\begin{array}{l}\text { 15.Time to reach health services } \\
\text { (min) }\end{array}$ & & & & & $<0.001$ \\
\hline$\leq 15$ & 837 & 34.53 & 1 & & \\
\hline $\begin{array}{l}>15 \\
\text { 16. Travelling cost make a burden }\end{array}$ & 364 & 46.54 & 1.6 & $1.28-2.12$ & $<0.001$ \\
\hline Not a burden & 1010 & 34.85 & 1 & & \\
\hline burden & 191 & 56.08 & 2.39 & $1.74-3.27$ & \\
\hline $\begin{array}{l}\text { 17. Burden of Medical Service } \\
\text { costs }\end{array}$ & & & & & $<0.001$ \\
\hline Not a burden & 905 & 33.59 & 1 & & \\
\hline burden & 296 & 52.22 & 2.16 & $1.65-2.82$ & \\
\hline
\end{tabular}

IMJM Volume 18 No.3, December 2019 
Table 3: Multivariate analysis for factors associated with Depression using $\operatorname{GLMM}(n=1,201)$

\begin{tabular}{|c|c|c|c|c|c|c|}
\hline Characteristics & No & \% of Dep & $\begin{array}{l}\text { Crude } \\
\text { OR }\end{array}$ & $\begin{array}{l}\text { Adjusted } \\
\text { OR }\end{array}$ & $95 \% \mathrm{CT}$ & p-value \\
\hline 1. Floor area of the house $\left(\mathrm{m}^{2}\right)$ & & & & & & $<0.001$ \\
\hline$>100$ & 392 & 28.32 & 1 & 1 & & \\
\hline$\leq 100$ & 809 & 43.02 & 1.91 & 1.21 & $1.00-1.47$ & \\
\hline 2. Adequacy of Income & & & & & & $<0.001$ \\
\hline Adequate with or without Saving & 257 & 28.40 & 1 & 1 & & \\
\hline Inadequate with or without debt & 944 & 40.89 & 1.74 & 1.79 & $1.35-2.37$ & \\
\hline 3. Stress & & & & & & $<0.001$ \\
\hline Mild stress & 125 & 20.80 & 1 & 1 & & \\
\hline Moderate and severe stress & 1076 & 40.24 & 2.56 & 2.35 & $1.34-4.13$ & \\
\hline 4. Quality of Life & & & & & & $<0.001$ \\
\hline Good QOL & 322 & 24.22 & 1 & 1 & & \\
\hline Poor QOL & 879 & 43.34 & 3.39 & 2.18 & $1.36-3.51$ & \\
\hline 5.Burden of medical services costs & & & & & & $<0.001$ \\
\hline Not a burden & 908 & 33.59 & 1 & 1 & & \\
\hline Some what \& Very burden & 293 & 52.22 & 2.16 & 1.82 & $1.18-2.8$ & \\
\hline
\end{tabular}

\section{DISCUSSION}

The study showed that incidence of depression was $38.22 \%$ among rural to urban migrants in Yangon Region, Myanmar. This finding was lower than a study by Hiott and Qiu who showed that the incidence of depression were $41.6 \%{ }^{9}$ and $54.1 \%{ }^{10}$ among migrant farm workers and rural Chinese women, respectively. But this incidence was higher than another four studies of $10.8 \%^{3}, 17.1 \%^{11}, 16.3 \%{ }^{12}$ and $23.7 \% .^{13}$ All these studies were measured by CESD. Mental disorders commonly occurred and were often serious in many countries throughout the world. Treatment cost could be expensive for the employer and also the affected people. ${ }^{14}$

The majority of low- and middle-income countries which are facing internal migrations with a large need of mental health due to demographic and population changes, warrant exploration of the relationship between migration and depressive episodes. ${ }^{11}$ There is conflicting proof of the healthy migrant effect with respect to mental health. ${ }^{12}$

Migrant populations were susceptible to emotional distress and the expression of depressive disorders while instantaneously suffering from disparities in health and access to care. ${ }^{11}$ Migrants with inadequate income with or without debt were 1.79 (95\% Cl: 1.35-2.37) times more likely to suffer from depression than those who received adequate income with or without saving. A profound association was found between having adequate income and depression. Participants who were poor with inadequate income faced various social and financial problems. Having sufficient income is important to avoid depression. Adequate regular income could reduce stress and depression.

Participants living in their houses with floor surface area, smaller than $100 \mathrm{~m}^{2}$ were more likely with 1.21 (95\% Cl: 1.00-1.47) times more chance to get depression than those lived more than $100 \mathrm{~m}^{2}$. Migrants living in substandard and unsafe housing may contribute to poor health status including mental health because shelter is the basic physiological need for human. ${ }^{15}$

The study pointed out that participants with moderate and severe stress were $2.35(95 \% \mathrm{Cl}$ : 1.34 4.13) times higher odds of having depression. This finding was similar to a study done in China, where migrant workers experienced more stress that resulted in depression (OR 2.75, $95 \% \mathrm{Cl} 1.47-5.14)^{16}$. 
A study done in United States among farmworkers, showed that stressful working conditions were associated with depression $(B=.325 \mathrm{P}=0.000) .{ }^{9} \mathrm{~A}$ possible explanation for this finding could be unemployment or underemployment, loss of social status, loss of family and community social supports in newly migrate area. ${ }^{4}$ The process of familiarizing to transformed situation in life, environment and culture is too stressful. ${ }^{17}$ Many previous studies have showed that migration caused accumulative stress that gradually lead to depression.

Concerning accessibility to health services, this study revealed that migrants with burden of medical service cost were $1.82(95 \% \mathrm{Cl}: 1.18-2.8)$ times higher odds of having depression. Access to health services have powerful effect on each aspect of the mental health. This finding was similar to the studies done in Myanmar; burden of medical services costs among PLWHA was strongly associated with depression (AOR 2.24, 95\% Cl $=1.29-3.88)^{18}$ and ( AOR $2.04,95 \% \mathrm{Cl}=1.65$ to 2.53 ). ${ }^{19}$ Affordability is not only on the direct medical service cost but also on the indirect cost such as transportation costs. Expenditures on food and lodging are now reflected as significant factors for access to healthcare and are directly associated with dimensions of poverty. ${ }^{20}$ In Myanmar, there is no health insurance system until now, thus out-of-pocket payments for the healthcare provision was $62 \% .{ }^{21}$

As migration flows increase worldwide, there are at least one billion migrants across the world. ${ }^{22}$ Immigrants are a vulnerable population at high possibility of poor physical and mental health consequences and inadequate health care. ${ }^{23}$

\section{CONCLUSION}

About two in five of the migrant workers suffered depression. This study concluded that socioeconomic disparities such as adequacy of income and living space were strongly associated with depression. Poor quality of life and burden of medical services costs were also associated with depression. Thus, to fulfill the sustainable development goals, it is important to make investment on mental health of the migrant workers. This finding could be applied for healthy public policy makers as a baseline in developing appropriate strategies to address migrants' health including mental health by promoting the social networking among internal migrant population and relevant sector both public and private sectors.

\section{LIMITATION OF THE STUDY}

This cross sectional study design does not allow the cause and effect relationships between the various factors and depression. This study was conducted among migrant workers between 18 and 59 years of aged living in Yangon Region and could not be generalized to all the migrant workers in Myanmar.

\section{SOURCE OF FUNDING}

The authors received no financial support for the research and publication of this article.

\section{CONFLICTS OF INTEREST}

The authors declare no conflict of interest.

\section{REFERENCES}

1. Rozental Y. Access to Health Care among Migrants in Central Asia. J Immigr Minor Health 2014 December; 16(6) 1138-1148

2. Topal K, Eser E, Sanberk I, Bayliss E, Saatci E. Challenges in access to health services and its impact on quality of life: a randomised population-based survey within Turkish speaking immigrants in London Health and Quality of Life Outcomes 2012, 10:11

3. Dai J, Floor G, Hospital P, Po T, Hospital SK, Mental $S$, et al. Internal migration, mental health, and suicidal behaviors in young rural Chinese. Soc Psychiatry Psychiatr Epidemiol 2015 April; 50(4) 621-631

4. Kirmayer LJ, Narasiah L, Munoz M, Rashid M, Ryder AG, Guzder J, et al. Common mental health problems in immigrants and refugees: General approach in primary care. Cmaj. 2011; 183(12):959-67.

5. Chen J, Chen S, Landry PF. Urbanization and Mental Health in China: Linking the 2010 Population Census with a Cross-Sectional Survey. Int J Environ Res Public Health 2015; 9012-24.

6. Anjara SG, Nellums LB, Bonetto C, Bortel T Van. Stress, health and quality of life of female migrant domestic workers in Singapore: a cross-sectional study. BMC Women's Health 
1798 DOI 101186/s12905-017-0442-7. 2017; 1 14.

7. Bloch DA, Larsen MD. A SIMPLE METHOD OF SAMPLE SIZE CALCULATION FOR LINEAR AND LOGISTIC REGRESSION. 1998; 1634(October 1997):1623-34.

8. DIVISION OF MENTAL HEALTH AND PREVENTION OF SUBSTANCE ABUSE, WORLD HEALTH ORGANIZATION. PROGRAMME ON MENTAL HEALTH WHOQOL User Manual. 1998.

9. Hiott $A E$, Grzywacz JG, Davis SW, Quandt SA, Arcury TA. Migrant Farmworker Stress : Mental Health Implications. Natl Rural Health Assoc. 2008

10. Qiu P, Caine ED, Hou F, Cerulli C, Wittink MN. Depression as Seen through the Eyes of Rural Chinese Women: Implications for Help-seeking and the Future of Mental Health Care in China. J Affect Disorder 2018 February; 22738 $-47$

11. Checkley W, Bennett IM, Miranda JJ. DEPRESSIVE MOOD AMONG WITHIN-COUNTRY MIGRANTS IN PERIURBAN SHANTYTOWNS OF LIMA, PERU. J Immigr Minor Health Author manuscript; available PMC 2016 May 04. 2016;

12. Straiton M, Grant JF, Winefield HR, Taylor A. Mental health in immigrant men and women in Australia: the North West Adelaide health study. BMC Public Health 2014, 141111 http// www. biomedcentral.com/1471-2458/14/1111. 2014

13. Peiyuan Qiu, Eric Caine, Yang Yang, Quan Chen, Jin $\mathrm{Li}$ and $\mathrm{XM}$. Depression and Associated Factors in Internal Migrant Workers in China. J Affect Disord 2011 November; 134 (1-3) 198-207

14. Kessler RC, Aguilar-gaxiola S, Alonso J, Chatterji S, Lee S, Ormel J, et al. The global burden of mental disorders: An update from the WHO World Mental Health (WMH) Surveys. NIH Public Access Author Manuscript Epidemiology Psichiatric Soc. 2009; 18(1):2333.

15. Beutel $M E$, Jünger $C$, Klein $E M$, Wild $P$, Lackner KJ, Blettner $M$, et al. Depression , anxiety and suicidal ideation among $1^{\text {st }}$ and $2^{\text {nd }}$ generation migrants - results from the Gutenberg health study. BMC Psychiatry [Internet]. 2016; 1-10. Available from: http:// dx.doi.org/10.1186/s12888-016-0995-2

16. Wong DFK, He X, Leung G, Lau Y, Chang Y. Mental health of migrant workers in China:
Prevalence and correlates. Soc Psychiatry Psychiatr Epidemiology. 2008; 43(6):483-9.

17. WHO 2018. Mental health promotion and mental health care in refugees and migrants.

18. Hnin Su Wai. Stigmatization toward HIV/AIDS and Depression among People Living with HIV/ AIDS in Yangon, Myanmar. [MPH thesis]. Khon Kaen University; 2018.

19. Min Kyi Zin. Socioeconomic Determinants on Quality of Life of PLWHA in Ayeyarwaddy Region, Myanmar. [MPH thesis]. Khon Kaen University; 2018.

20. Peters DH, Garg A, Bloom G, Walker DG, Brieger WR, Hafizur Rahman M. Poverty and access to health care in developing countries. New York Acad Sci. 2008;1136:161-71.

21. Health in Myanmar. Ministry of Health and Sport, Union of Republic of Myanmar. 2017.

22. Yang $\mathrm{PQ}$, Hwang $\mathrm{SH}$. Explaining Immigrant Health Service Utilization. SAGE Open. 2016;6 (2):215824401664813.

23. Melberg A, Onarheim KH, Spjeldnæs AO, Miljeteig I. Towards universal health coverage for undocumented migrants. Tidsskr den Nor Laegeforening. 2018; 138(1):1-6. 